\title{
Mortality after major amputation in elderly patients with critical limb ischemia
}

\author{
This article was published in the following Dove Press journal: \\ Clinical Interventions in Aging \\ Number of times this article has been viewed
}

\author{
Sanne Klaphake ${ }^{1,2}$ \\ Kevin de Leur ${ }^{\prime}$ \\ Paul GH Mulder ${ }^{1,3}$ \\ Gwan H Ho' \\ Hans G de Groot' \\ Eelco J Veen' \\ Hence JM Verhagen ${ }^{2}$ \\ Lijckle van der Laan' \\ 'Department of Surgery, Amphia \\ Hospital, Breda, ${ }^{2}$ Department of \\ Vascular Surgery, Erasmus University \\ Medical Center, Rotterdam, ${ }^{3}$ Amphia \\ Academy, Amphia Hospital, Breda, \\ the Netherlands
}

Background: Owing to the aging population, the number of elderly patients with critical limb ischemia (CLI) has increased. The consequence of amputation is immense. However, at the moment, information about the mortality after amputation in the elderly vascular patients is unknown. For this reason, this study evaluated mortality rates and patient-related factors associated with mortality after a major amputation in elderly patients with CLI.

Methods: From 2006 to 2013, we included patients aged $>70$ years who were treated for chronic CLI by primary or secondary major amputation within or after 3 months of initial therapy (revascularization or conservative management). Outcome measurements were mortality after major amputation and factors associated with mortality (age, comorbidity and timing of amputation).

Results: In total, 168/651 patients (178 legs; 26\%) underwent a major amputation. Patients were stratified by age: $70-80$ years $(n=86)$ and $>80$ years $(n=82)$. Overall mortality after major amputation was $44 \%, 66 \%$ and $85 \%$ after 1,3 and 5 years, respectively. The 6-month and 1 -year mortality in patients aged 80 years or older was, respectively, $59 \%$ or $63 \%$ after a secondary amputation $<3$ months versus $34 \%$ and $44 \%$ after a secondary amputation $>3$ months. Per year of age, the mortality rate increased by $4 \%(P=0.005)$. No significant difference in mortality after major amputation was found in the presence of comorbidity or according to Rutherford classification. Conclusion: Despite developments in the treatment of CLI by revascularization, amputation rates remain high and are associated with tremendous mortality rates. Secondary amputation after a failed attempt of revascularization causes a higher mortality. Further research concerning timing of amputation and patient-related outcome is needed to evaluate if selected patients might benefit from primary amputation.

Keywords: peripheral arterial disease, aged, limb ischemia, primary amputation, octogenarians, patient selection

\section{Introduction}

In spite of ongoing improvements in the management of critical limb ischemia (CLI) by (endovascular) revascularization techniques, major amputations continue to be performed. CLI is the most advanced manifestation of peripheral arterial disease (PAD) as it is a chronic, arterial occlusive disease. ${ }^{1}$ The incidence of CLI is estimated to be $500-1,000 / 1$ million every year, which accounts for $\sim 1 \%$ of the total number of patients with PAD. ${ }^{2}$ Within a year after the onset of CLI, $\sim 25 \%$ of the patients require an amputation. ${ }^{1}$ Amputations rates increase with higher Rutherford classification. In patients with Rutherford 6, the amputation risk is almost $60 \%$ within 1 year. ${ }^{3}$ Patients with diabetes have an even higher need for a major amputation, up to five to ten times, compared to nondiabetic patients with PAD. ${ }^{4,5}$ In general, amputation for CLI will be performed if other therapeutic options are unavailable or have failed.
Correspondence: Sanne Klaphake Department of Surgery, Amphia Hospital, PO Box 90518, 4800 RK Breda, the Netherlands

Tel +3I 765951562

Email sklaphake@amphia.nl (c) (1) (5) 2017 Klaphake et al. This work is published and licensed by Dove Medical Press Limited. The full terms of this license are available at https://www.dovepress.com/terms.php
and incorporate the Creative Commons Atribution - Non Commercial (unported, v3.0) License (http://creativecommons.org/licenses/by-nc/3.0/). By accessing the work you

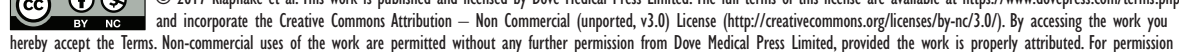
for commercial use of this work, please see paragraphs 4.2 and 5 of our Terms (https://www.dovepress.com/terms.php). 
The implicit goal of amputation is to relieve pain, to stop ongoing gangrene and/or infection and to create an environment in which a wound can heal.

Besides severe morbidity, CLI is also associated with high mortality rates of up to $25 \%$ after 1 year and up to $64 \%$ after 4 years of onset. ${ }^{1,3}$ Patients with CLI are often elderly patients with significant comorbidities and are prone to complications such as myocardial infarction and stroke. ${ }^{6}$ Survival rates after major amputation in these patients are low, with mortality rates up to $37 \%$ during 1 year and $49 \%$ after 2 years. ${ }^{7-9}$

The aim of this study was to evaluate mortality rates after major amputation in elderly patients with CLI. As major amputation is sometimes unavoidable in the treatment of CLI, we also attempted to gain a better understanding of the effect of timing of major amputation on mortality. Furthermore, we aimed to assess patient-related factors associated with mortality, such as age, gender, Rutherford classification and comorbidity.

\section{Methods}

\section{Patients}

From January 2006 to December 2013, consecutive patients aged 70 years or older, treated for CLI by major amputation in a single large teaching hospital in the Netherlands, were retrospectively analyzed. Data were retrieved from electronic patient's records, obtained by using the Dutch diagnosis code for Rutherford classification stages 4-6. To compare baseline data and mortality rates, patients treated by conservative management, endovascular revascularization or surgical revascularization were also included. Patient characteristics, including age, gender, history of vascular disease (PAD, cardiovascular disease, cerebrovascular disease), comorbidity and risk factors, were registered. Smoking was recorded in case of current smoking. Hypertension was defined as use of antihypertensive medication. Diabetes mellitus was defined as use of antidiabetic medication. Chronic kidney disease was defined as an estimated glomerular filtration rate $(\mathrm{eGFR})<60 \mathrm{~mL} / \mathrm{min}$ as calculated from serum creatinine levels using the Modification of Diet in Renal Disease (MRD) formula. Other comorbidities included were past or current cerebrovascular disease (transient ischemic attack or ischemic stroke), ischemic heart disease (cardiac ischemic event, angina or prior coronary intervention), heart failure and pulmonary disease (chronic obstructive pulmonary disease [COPD] or others). Rutherford classification was dichotomized as scores 5 and 6 (ulcers and gangrene) versus score 4 (ischemic rest pain). The Trans-Atlantic Inter-Society Consensus (TASC) classification was based on duplex ultrasound, angiography or magnetic resonance angiography (MRA). ${ }^{1}$
Patients presenting with acute symptoms were excluded. In case both legs were affected during the study period, we included them as separate records linked to the patient.

According to the local board of the Amphia Hospital, no approval of an ethics committee and no informed consent were required. The study complies with the Declaration of Helsinki on research ethics, and patient data were handled confidentially.

\section{Diagnosis and treatment}

Standard workup for all patients suspected of having PAD included ankle-brachial index (ABI) measurement. Duplex ultrasound or MRA was performed in selected patients to evaluate treatment options. All patients received statins and antiplatelet medication, unless an indication for anticoagulation was present. A dedicated multidisciplinary vascular team regularly reviewed the patients. The choice of therapeutic management was made in consensus based on technical possibilities and general health in individual patients. For the management of CLI patients, in general, an "endovascular first" strategy was followed. Stent was used if indicated. If the target lesion was not suitable for endovascular revascularization, surgical revascularization was performed. Surgical procedures included bypass or endarterectomy. Before surgical intervention, all patients were seen by a cardiologist to evaluate operative risk and to optimize cardiac status. Conservative treatment was followed in patients with significant comorbidities (unfit for surgery) who responded favorably on pain reduction therapy and in patients who did not consent to other therapies.

\section{Definitions}

Major amputation was defined as all amputations above the ankle. ${ }^{1}$ Time of major amputation during the study period was categorized into three classes: 1) primary amputation; 2) secondary amputation within 3 months after primary intervention and 3 ) secondary amputation after 3 months following primary intervention. Primary amputation is defined as amputation without an earlier attempt at revascularization and may be indicated in the absence of outflow vessels, in case of extensive gangrene or infection, or in the presence of severe comorbidities. This in contrast to secondary amputation is indicated when vascular interventions have failed or when the limb continues to deteriorate despite the presence of a successful revascularization. ${ }^{1}$ Secondary amputation within 3 months was considered to be the result of a failed attempt of primary treatment (conservative management, endovascular 
revascularization or surgical revascularization). Secondary amputation after 3 months of initial therapy was considered to be progression of the disease. Indications for amputation were non-reconstructable arterial occlusive disease, extensive gangrene or severe infection present at initial vascular evaluation and patients who were unfit for reconstruction due to flexion contracture, significant comorbidities or terminal illness.

Conservative treatment was considered to be adequate analgesia, antibiotics and wound debridement or minor amputation (below the ankle).

\section{Outcome end points}

After discharge follow-up was continued in the outpatient clinic, patients were evaluated for reinterventions and survival until December 2014. Primary outcome was mortality after major amputation. Mortality data were obtained using a community-based registry, the COMPET\&T database from the company T\&T Eindhoven. Secondary outcome measures were effect of timing of amputation on mortality and patientrelated factors associated with mortality.

\section{Statistical analysis}

Categorical baseline characteristics of the patient group were reported as (relative) frequencies. Numeric variables were reported as mean and standard deviation values or, when appropriate, as median and range values. As the survival analyses were related to (time of) major amputation and should only be concerned with unique patients, the following rules for selecting the leg of interest were applied for patients with both legs affected. The amputated leg was included. If both or no legs were amputated, the earlier treated leg was chosen. Possible occurrence and time of major amputation of the contralateral leg were also taken as explanatory variables in the analyses.

In survival analyses after major amputation, the explanatory variable of interest was time of amputation: primary intervention and secondary amputation $<3$ months and $>3$ months of initial therapy (revascularization or conservative management). In this subgroup, follow-up started at the moment of major amputation, which was defined as time zero. Survival probabilities were estimated using the product-limit (KaplanMeier) method. Effect of time of amputation was tested using the log-rank test. In order to take account of the possibly confounding effect of covariables, we used the Cox proportional hazards regression model. The following covariables were entered along with the categorical variable time of amputation: age in years as time-dependent covariable, amputation of the contralateral leg $(\mathrm{Y} / \mathrm{N})$ as time-dependent indicator variable, diabetes $(\mathrm{Y} / \mathrm{N})$, hypertension $(\mathrm{Y} / \mathrm{N})$, renal failure $(\mathrm{Y} / \mathrm{N})$, heart failure $(\mathrm{Y} / \mathrm{N})$ and Rutherford score (5 and 6 vs 4 ).

Effects of the explanatory variables in the Cox proportional hazards model on survival were expressed by means of mortality rate ratios (RRs). Estimated effects were considered statistically significant if their $P$-values dropped to $<0.05$. Statistical analyses were performed using SPSS 22.0.

\section{Results}

\section{Patient selection and patient characteristics}

During the study period, 651 patients (685 legs) were treated for CLI. In 168 (26\%) patients, a major amputation was performed (Figure 1). In 10 patients, a major amputation of the contralateral leg was also performed. Baseline characteristics are shown in Table 1. The median age at the time of major amputation was 80 years (range $70-95$ years). In the major amputation group, $58 \%$ of patients were male $(P=0.019)$. Presence of diabetes was $61 \%$ in the amputation group versus $45 \%$ in the nonamputation group $(P<0.001)$. Renal failure was present in $27 \%$ versus $17 \%$ patients in the amputation group and non-amputation group, respectively $(P=0.003)$. A higher Rutherford classification was found in the amputation group $(P<0.001)$, and the number of outflow arteries was less in patients who underwent an amputation $(P<0.001)$ compared to the non-amputation group.

Out of the 178 major amputations, a primary amputation was performed in 47 (26\%) cases. Indications for primary amputation are listed in Table 2. A secondary amputation was performed in 131 cases, with 70 cases within 3 months and 61 cases after 3 months following primary treatment (Figure 1). Initial treatments before secondary major amputations were conservative $(n=21)$, endovascular revascularization $(n=72)$ and surgical $(n=38)$. In seven $(4 \%)$ patients, a higher level of amputation was performed after a major amputation. The TASC classification was similar among the various treatment groups (aortoiliac: $P=0.22$, femoropopliteal: $P=0.40$ ).

\section{Mortality after major amputation}

Total follow-up in the subgroup of 168 major amputation patients amounted to 3,550 person-months during which 132 deaths occurred, yielding an overall mortality rate of $0.45 /$ patient/year. All-cause overall mortality after major amputation was $44 \%, 66 \%$ and $85 \%$ after 1,3 and 5 years, 


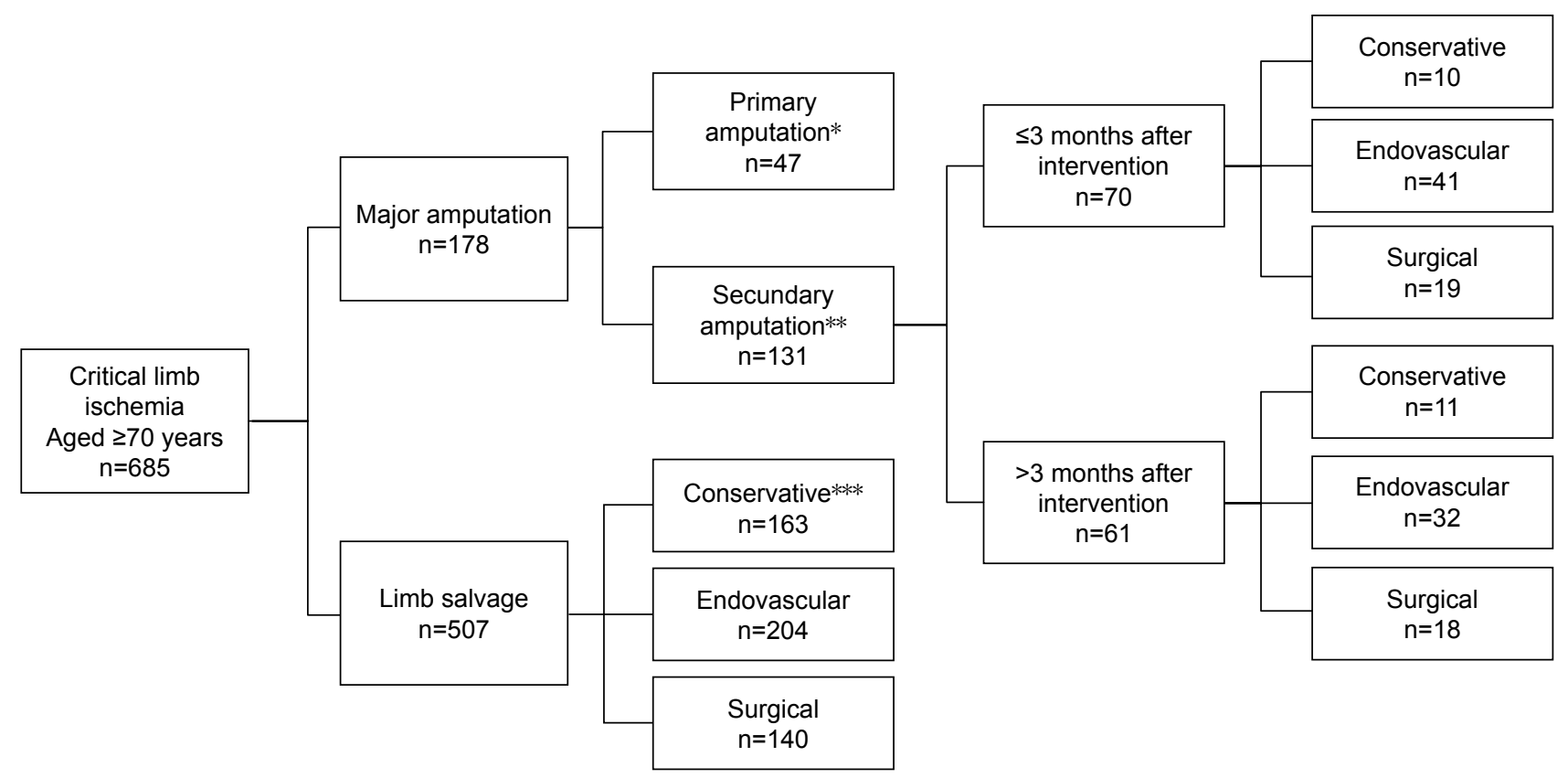

Figure I Patient selection.

Notes: Numbers presented are the number of treated legs. *Primary amputation: no attempt of revascularization. **Secondary amputation: amputation after revascularization/ conservative management/minor amputation. ${ }^{* *}$ Conservative management includes analgesia, antibiotics, wound care and minor amputation.

respectively (Kaplan-Meier estimates; Table 3). All-cause mortality in patients treated for CLI without amputation was $27 \%, 49 \%$ and $61 \%$ after 1,3 and 5 years. Mortality after primary treatment in patients who underwent an amputation (primary or secondary during follow-up) and in patients treated without amputation (conservative, endovascular or surgical) is presented in Figure $2(P<0.001)$.

There was no significant difference in mortality in primary versus secondary amputation (Kaplan-Meier estimates, $P=0.6$; Figure 3). The difference in mortality rates between the amputation time categories is presented in Table 4 (log-rank test; $P=0.67$ ). In all, 1 -year mortality after major amputation was $41 \%$ in patients aged $70-79$ years and $48 \%$ in patients aged $\geq 80$ years $(P=0.073$, log-rank test; Table 4$)$. Time of amputation (primary or secondary amputation) adjusted for age also did not reach significance $(P=0.59$, stratified log-rank-test).

Estimated mortality RRs resulting from Cox proportional hazards regression are presented in Table 5. The effect of all variables simultaneously on mortality was significant $(P=0.002)$. The effect of time of major amputation on survival was not significant (overall $P=0.59$ ), adjusted for the other variables presented in the table. Relative to patients undergoing primary amputation (45 patients), the mortality RRs of amputations performed within 3 months (67 patients) or later (56 patients) after primary intervention were 1.26 $(P=0.32)$ and $1.20(P=0.46)$, respectively. The $\mathrm{RR}$ of the effect on mortality of a major amputation of the contralateral leg taking place (12 patients) was $1.28(P=0.60)$. This variable is time dependent as its effect only holds after amputation of the contralateral leg had taken place. The effect of aging showed an RR of 1.04: per year of age, the mortality rate increased by $4 \%(P=0.005)$. Other variables in the model such as Rutherford classification and comorbidity (diabetes mellitus, renal failure, hypertension, heart failure) had no significant effect on mortality after major amputation (Table 5).

\section{Discussion}

The survival after major amputation in elderly patients aged 70 years or older with CLI was poor, with mortality rates of $44 \%$ after 1 year and $85 \%$ after 5 years. The mortality rates were higher in patients who underwent a major amputation compared to patients treated by revascularization or by conservative treatment. The survival after major amputation in patients with CLI is poor; however, only a few studies reported on mortality rates after amputation in elderly patients. Pell and Stonebridge ${ }^{9}$ described an overall 1-year mortality rate of $37 \%$ following major amputation in elderly. The lower mortality might be due to the younger population compared to our study. In addition, a considerable number of patients who underwent a major amputation were non-ambulatory pre operation. Non-ambulatory status is a negative predictor of outcome after major amputation. ${ }^{8}$ 
Table I Patient characteristics

\begin{tabular}{|c|c|c|c|}
\hline Variable & $\begin{array}{l}\text { Amputation, } \\
n=168(\%)\end{array}$ & $\begin{array}{l}\text { No amputation, } \\
n=483(\%)\end{array}$ & $P$-value \\
\hline \multicolumn{4}{|l|}{ Age, years } \\
\hline $70-79$ & $86(5 I)$ & $255(53)$ & \multirow[t]{2}{*}{0.69} \\
\hline$>80$ & $82(50)$ & $228(48)$ & \\
\hline \multicolumn{4}{|l|}{ Gender } \\
\hline M & $98(58)$ & $229(48)$ & \multirow[t]{2}{*}{0.019} \\
\hline $\mathrm{F}$ & $70(42)$ & $254(52)$ & \\
\hline \multicolumn{4}{|c|}{ Rutherford classification } \\
\hline Rutherford 4 & $34(20)$ & $169(35)$ & \multirow[t]{2}{*}{$<0.001$} \\
\hline Rutherford 5-6 & $134(80)$ & $314(65)$ & \\
\hline \multicolumn{4}{|c|}{ Risk factors and comorbidity } \\
\hline Smoking & $42(26)$ & $156(32)$ & 0.056 \\
\hline Hypertension & $117(70)$ & $311(65)$ & 0.24 \\
\hline Diabetes & $103(6 I)$ & $216(45)$ & $<0.001$ \\
\hline Renal failure & $46(27)$ & $82(17)$ & 0.003 \\
\hline Heart failure & $65(39)$ & $119(25)$ & 0.001 \\
\hline COPD & $51(30)$ & $124(26)$ & 0.36 \\
\hline \multicolumn{4}{|l|}{ Ambulatory status } \\
\hline Ambulatory & $103(6 I)$ & $387(80)$ & \multirow[t]{3}{*}{$<0.001$} \\
\hline Non-ambulatory & $36(22)$ & $26(5)$ & \\
\hline Missing & $29(17)$ & $70(15)$ & \\
\hline \multicolumn{4}{|c|}{ TASC classification - aortoiliac } \\
\hline No lesion & $102(6 \mathrm{I})$ & $28 \mid(58)$ & \multirow[t]{5}{*}{0.26} \\
\hline Type A & $17(10)$ & $75(16)$ & \\
\hline Type B & $10(6)$ & $30(6)$ & \\
\hline Type C & $4(2)$ & $17(4)$ & \\
\hline Type D & $5(3)$ & $31(6)$ & \\
\hline \multicolumn{4}{|c|}{ TASC classification - femoropopliteal } \\
\hline No lesion & $16(10)$ & $40(8)$ & \multirow[t]{5}{*}{0.25} \\
\hline Type A & $16(10)$ & $50(10)$ & \\
\hline Type B & $60(36)$ & $173(36)$ & \\
\hline Type C & $31(19)$ & $129(27)$ & \\
\hline Type D & $25(15)$ & $52(\mathrm{II})$ & \\
\hline \multicolumn{4}{|c|}{ Outflow tibial arteries } \\
\hline None & II (7) & $17(4)$ & \multirow[t]{5}{*}{$<0.001$} \\
\hline I vessel & $73(44)$ & $135(28)$ & \\
\hline 2 vessels & $42(25)$ & $153(32)$ & \\
\hline 3 vessels & $14(8)$ & $114(24)$ & \\
\hline Missing & $28(17)$ & $64(13)$ & \\
\hline
\end{tabular}

Abbreviations: $\mathrm{M}$, male; $\mathrm{F}$, female; COPD, chronic obstructive pulmonary disease; TASC, Trans Atlantic InterSociety Consensus.

Analysis of time of amputation revealed no significant difference in death between primary and secondary amputation within 3 months after revascularization. This suggests that an attempt of revascularization can be performed. This corresponds to the results of Faglia et a ${ }^{10}$ who reported that the mortality in patients who had primary amputation in diabetics

Table 2 Indications for primary major amputation $(n=47)$

\begin{tabular}{ll}
\hline Indication & $\mathbf{n}(\%)$ \\
\hline Non-reconstructable & $18(38)$ \\
Progression wound/extensive gangrene & $14(30)$ \\
Sepsis & $4(9)$ \\
Unfit for intervention & $11(23)$ \\
\hline
\end{tabular}

Table 3 Mortality after major amputation

\begin{tabular}{lllll}
\hline & Time & \multicolumn{3}{l}{$\begin{array}{l}\text { Overall mortality in the major } \\
\text { amputation subgroup of } \mathbf{1 6 8} \text { patients }\end{array}$} \\
\cline { 3 - 5 } & & \% (SE) & Deaths (n) & $\begin{array}{c}\text { Remaining } \\
\text { at risk (n) }\end{array}$ \\
\hline Major & 30 days & $14.3(2.7)$ & 24 & 144 \\
amputation & 6 months & $38.2(3.8)$ & 64 & 103 \\
& I year & $44.3(3.8)$ & 74 & 90 \\
& 3 years & $65.6(3.8)$ & 106 & 39 \\
& 5 years & $85.1(3.4)$ & 126 & 13 \\
\hline
\end{tabular}

Abbreviation: SE, standard error.

with CLI was worse than those who underwent revascularization and then an amputation. Interestingly, in our study, a trend of a higher mortality is seen, especially in patients older than 80 years. The 1-year mortality was $63 \%$ in this subgroup. This is much higher than the $30 \%$ in primary amputations and $44 \%$ in late ( $>3$ months) amputations. The 30-day mortality was even three to almost six times higher. Some had nonsuccessful interventions, and some lost their legs either due to occluded revascularization or despite patent bypasses or treated arteries. Particularly, these patients might benefit from primary amputation. Conservative treatment likely helped to decrease perioperative mortality after primary amputations, by simply not operating. These results suggest that failed attempt of revascularization should be avoided in octogenarians. In selected patients, primary amputation may be a reasonable therapeutic strategy, as it could potentially prevent repetitive interventions and hospital admissions. Owing to the design of the study, it was not possible to make

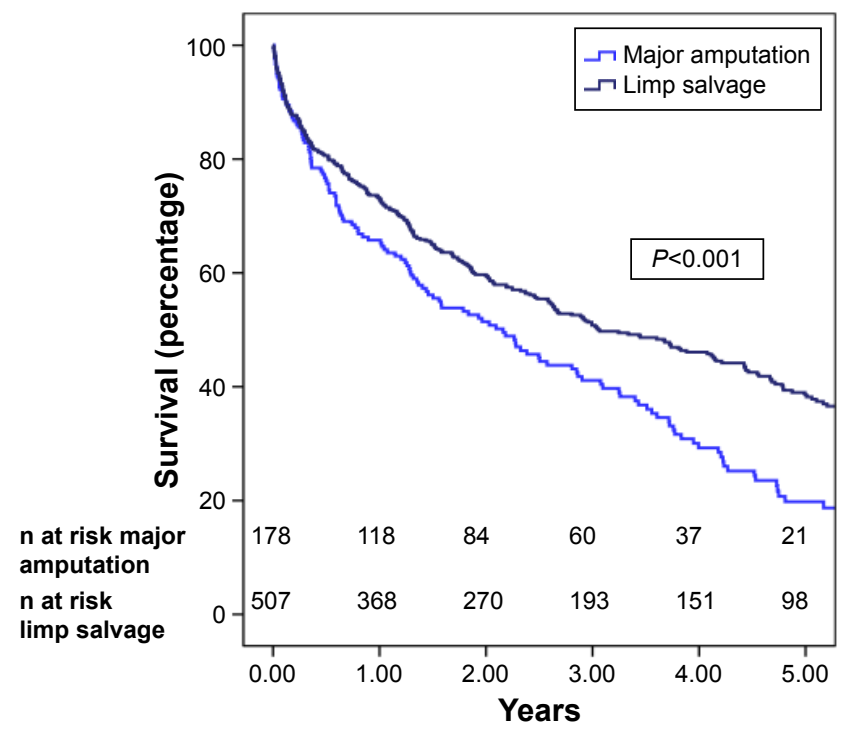

Figure 2 Kaplan-Meier curve.

Note: Mortality after primary treatment in patients who underwent a major amputation (primary and secondary; $n=168$ ) versus patients treated without amputation $(n=505)$. 


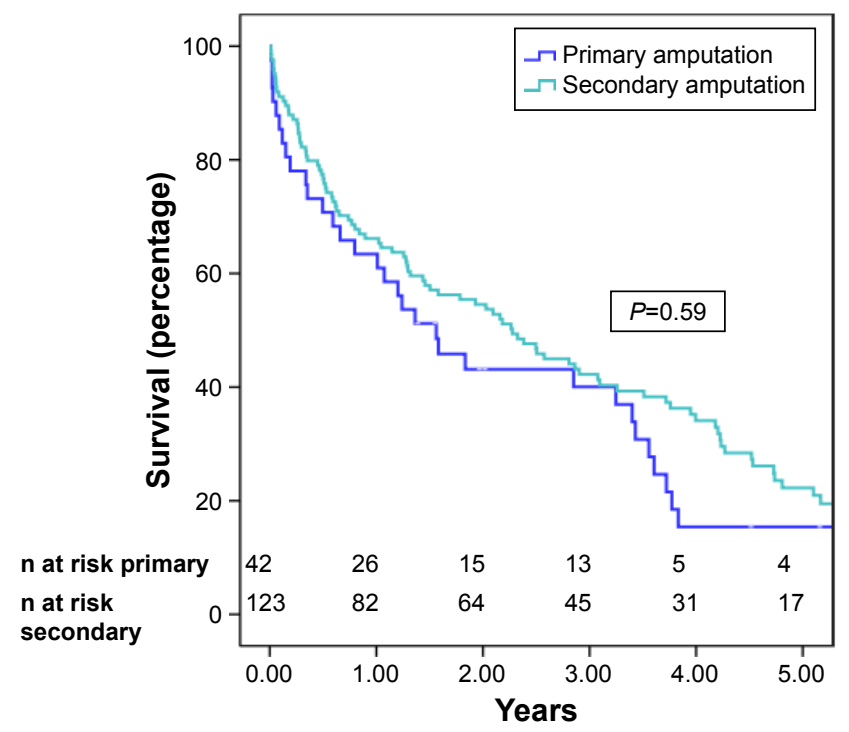

Figure 3 Kaplan-Meier curve.

Note: Mortality after primary amputation and secondary amputation $(n=168)$.

a prediction model for failure of revascularization. Further research should indicate if timing of amputation has an influence on mortality. In addition, patient-related outcomes as quality of life should be assessed.

Table 4 Cumulative mortality probabilities of primary amputation and secondary amputation in patients aged 70-79 years versus $\geq 80$ years

\begin{tabular}{|c|c|c|c|}
\hline \multirow[t]{2}{*}{ Timing amputation } & \multirow[t]{2}{*}{ Time } & \multicolumn{2}{|l|}{ Mortality } \\
\hline & & 70-79 years & $\geq 80$ years \\
\hline & & $n=84$ & $n=84$ \\
\hline \multirow[t]{6}{*}{ Overall $(P=0.073)^{*}$} & 30 days & $13 \%$ & $15 \%$ \\
\hline & 6 months & $34 \%$ & $43 \%$ \\
\hline & I year & $41 \%$ & $48 \%$ \\
\hline & 3 years & $57 \%$ & $76 \%$ \\
\hline & 5 years & $80 \%$ & $91 \%$ \\
\hline & & $n=25$ & $\mathbf{n}=\mathbf{2 0}$ \\
\hline Primary amputations & 30 days & $12 \%$ & $5 \%$ \\
\hline \multirow[t]{5}{*}{$(P=0.67)^{*}$} & 6 months & $24 \%$ & $30 \%$ \\
\hline & I year & $44 \%$ & $30 \%$ \\
\hline & 3 years & $57 \%$ & $66 \%$ \\
\hline & 5 years & $84 \%$ & $91 \%$ \\
\hline & & $n=35$ & $n=32$ \\
\hline Amputation $<3$ months & 30 days & $17 \%$ & $28 \%$ \\
\hline \multirow[t]{5}{*}{ after intervention $(P=0.17)^{*}$} & 6 months & $37 \%$ & $59 \%$ \\
\hline & I year & $43 \%$ & $63 \%$ \\
\hline & 3 years & $54 \%$ & $80 \%$ \\
\hline & 5 years & $80 \%$ & $87 \%$ \\
\hline & & $n=24$ & $n=32$ \\
\hline Amputation $>3$ months & 30 days & $8 \%$ & $9 \%$ \\
\hline \multirow[t]{4}{*}{ after intervention $(P=0.35)^{*}$} & 6 months & $39 \%$ & $34 \%$ \\
\hline & I year & $39 \%$ & $44 \%$ \\
\hline & 3 years & $62 \%$ & $77 \%$ \\
\hline & 5 years & $72 \%$ & $88 \%$ \\
\hline
\end{tabular}

Note: $* P$-values are based on the log-rank test of the null hypothesis that survival is the same in both age groups.
Table 5 Estimated mortality RRs using Cox proportional hazards model in 168 patients of whom 132 died after major amputation

\begin{tabular}{lll}
\hline Variable & RR $(\mathbf{9 5} \% \mathbf{C I})$ & $P$-value \\
\hline $\begin{array}{l}\text { Time of amputation } \\
\quad \text { Primary amputation }\end{array}$ & $\mathrm{I}$ & 0.59 \\
$\quad$ Amputation within 3 months & $\mathrm{I} .26(0.8 \mathrm{I}-\mathrm{I} .95)$ & 0.32 \\
$\quad$ Amputation after 3 months & $\mathrm{I} .20(0.74-1.94)$ & 0.46 \\
Amputation of contralateral leg & $\mathrm{I} .28(0.50-3.27)$ & 0.60 \\
(time dependent) & & \\
Age in years (time dependent) & $\mathrm{I} .04(\mathrm{I} .0 \mathrm{I}-\mathrm{I} .07)$ & 0.005 \\
Diabetes mellitus & $\mathrm{I} .36(0.94-\mathrm{I} .97)$ & 0.10 \\
Renal failure & $\mathrm{I} .47(0.99-2.20)$ & 0.057 \\
Hypertension & $0.8 \mathrm{I}(0.54-\mathrm{I} .2 \mathrm{I})$ & 0.30 \\
Heart failure & $\mathrm{I} .42(0.98-2.05)$ & 0.063 \\
Rutherford classification & $\mathrm{I} .57(0.98-2.5 \mathrm{I})$ & $0.06 \mathrm{I}$ \\
\hline
\end{tabular}

Note: Significance of the model: $P=0.002\left(\chi^{2}=26.529\right.$ with nine $\left.d f\right)$.

Abbreviations: $R R$, rate ratio; df, degrees of freedom.

Revascularization of the lower extremity remains the treatment of choice for most patients with CLI. Therapeutic options have significantly increased after introduction and improvement of less invasive techniques such as endovascular therapy. ${ }^{11}$ Owing to these advances, there appears to be a decline in overall major amputation rates associated with a corresponding increase in revascularizations. Although technical advances may have resulted in a steadiness or even decrease in amputations, comparisons of total amputations over a longer period suggest an increase..$^{12}$ Presumably, this effect is attributable to an aging population, because of late referral to vascular surgeons, but perhaps more importantly, because there is no agreed upon definition of non-salvageable limb. ${ }^{13,14}$ An amputation rate of $26 \%$ as shown in our population is comparable to the amputation rate described by TASC II. ${ }^{1}$ Recently, a study containing a large cohort reported on the 1-year amputation rate in CLI within a wide range from $5 \%$ to $57 \%$ depending on Rutherford classification. ${ }^{3}$ These data are in accordance to our results. The amputation rate can be explained by the higher incidence of diabetes and renal failure and also the high non-ambulatory status in our study population. Additionally, the majority of the patients had a high Rutherford classification. Amputation frequencies up to $77 \%$ are reported in studies including patients with diabetics and CLI. ${ }^{10,15}$ Higher rates in these studies could be explained by a different pathophysiology of atherosclerosis in diabetic patients. In our population, the most common indication for primary amputation was extensive gangrene or non-reconstructable arteries (67\%). Unreconstructable vascular disease was the most common indication for secondary amputation, accounting for $\sim 53 \%$ of the patients, which corresponds to the $60 \%$ mentioned in TASC II. ${ }^{1}$ 
Treatment of CLI should be tailored to the individual patient. Therefore, initiating the most suitable therapy can be a challenge for vascular surgeons. Predictive risk factors might facilitate in the difficult decision-making. Outcome does not appear to be adversely influenced by system-related factors but is determined by patient-specific factors. Amputation is mostly performed in patients with serious comorbidity, severe wounds or gangrene and no revascularization options, which makes it a poor patient population in advance. Comorbidity, end-stage renal disease, major tissue loss, dependent living situation, non-ambulatory status and non-White ethnicity are reported to be significant patient-related risk factors for death after major primary amputation. ${ }^{16}$ Age was also reported to have an adverse effect on survival. ${ }^{9}$ Between the two age groups, 70-79 years and 80 years or older, no significant difference in mortality was observed $(P=0.073)$. When analyzing age as a continuous time variable however, our results showed age as a significant risk factor for mortality $(P=0.005)$. Besides age, there was a trend in renal failure $(P=0.057)$, heart failure $(P=0.063)$ and Rutherford classification $(P=0.061)$ as risk factors for death after major amputation. Aulivola et a $1^{17}$ found end-stage renal disease as a risk factor for death at 1 and 5 years $(51.9 \%$ and $14.4 \%$ vs $75.4 \%$ and $42.2 \% ; P<0.001)$. In contrast to our results, a recent meta-analysis showed that diabetes has an association with an increased risk of all-cause mortality in patients with CLI. ${ }^{18}$ The analysis reported a significant lower survival rate in patients with diabetes after a major amputation, whereas we found a higher mortality RR, nonetheless a nonsignificant effect on survival. The number of patients included in this study might be too small to show significance. In addition, no significant adverse effect of hypertension on mortality was found, with an RR of 0.81 . This might be the result of treatment of hypertension.

\section{Conclusion}

Despite developments in the treatment of CLI by revascularization, amputation rates remain high. Major amputations continue to be associated with tremendous mortality rates compared to conservative treatment, endovascular revascularization and surgical revascularization.

\section{Disclosure}

The authors report no conflicts of interest in this work.

\section{References}

1. Norgren L, HiattWR, Dormandy JA, Nehler MR, Harris KA, Fowkes FGR. Inter-society consensus for the management of peripheral arterial disease (TASC II). J Vasc Surg. 2007;45(1):S5-S67.

2. Catalano M. Epidemiology of critical limb ischaemia: north Italian data. Eur J Med. 1993;2(1):11-14.

3. Reinecke H, Unrath M, Freisinger E, et al. Peripheral arterial disease and critical limb ischaemia: still poor outcomes and lack of guideline adherence. Eur Heart J. 2015;36(15):932-938.

4. Carmona GA, Hoffmeyer P, Herrmann FR, et al. Major lower limb amputations in the elderly observed over ten years: the role of diabetes and peripheral arterial disease. Diabetes Metab. 2005;31(5):449-454.

5. Johannesson A, Larsson GU, Ramstrand N, Turkiewicz A, Wiréhn AB, Atroshi I. Incidence of lower-limb amputation in the diabetic and nondiabetic general population: a 10-year population-based cohort study of initial unilateral and contralateral amputations and reamputations. Diabetes Care. 2009;32(2):275-280.

6. Shammas NW. Epidemiology, classification, and modifiable risk factors of peripheral arterial disease. Vasc Health Risk Manag. 2007;3(2): 229-234.

7. Dormandy JA. Natural history of patients with peripheral occlusive arterial disease. Ann Chir Gynaecol. 1992;81(2):86-88.

8. Cruz CP, Eidt JF, Capps C, Kirtley L, Moursi MM. Major lower extremity amputations at a Veterans Affairs hospital. Am J Surg. 2003; 186(5):449-454.

9. Pell J, Stonebridge P. Association between age and survival following major amputation. The Scottish Vascular Audit Group. Eur J Vasc Endovasc Surg. 1999;17(2):166-169.

10. Faglia E, Clerici G, Clerissi J, et al. Long-term prognosis of diabetic patients with critical limb ischemia: a population-based cohort study. Diabetes Care. 2009;32(5):822-827.

11. Bradbury AW, Adam DJ, Bell J, et al. Bypass versus Angioplasty in Severe Ischaemia of the Leg (BASIL) trial: an intention-to-treat analysis of amputation-free and overall survival in patients randomized to a bypass surgery-first or a balloon angioplasty-first revascularization strategy. J Vasc Surg. 2010;51(5 suppl):5S-17S.

12. Karlstrom L, Bergqvist D. Effects of vascular surgery on amputation rates and mortality. Eur J Vasc Endovasc Surg. 1997;14(4):273-283.

13. Dormandy J, Heeck L, Vig S. The fate of patients with critical leg ischemia. Semin Vasc Surg. 1999;12(2):142-147.

14. Rowe VL, Lee W, Weaver FA, Etzioni D. Patterns of treatment for peripheral arterial disease in the United States: 1996-2005. J Vasc Surg. 2009;49(4):910-917.

15. Feinglass J, Pearce WH, Martin GJ, et al. Postoperative and late survival outcomes after major amputation: findings from the Department of Veterans Affairs National Surgical Quality Improvement Program. Surgery. 2001;130(1):21-29.

16. Abou-Zamzam AM Jr, Gomez NR, Molkara A, et al. A prospective analysis of critical limb ischemia: factors leading to major primary amputation versus revascularization. Ann Vasc Surg. 2007;21(4):458-463.

17. Aulivola B, Hile CN, Hamdan AD, et al. Major lower extremity amputation: outcome of a modern series. Arch Surg. 2004;139(4):395-399. discussion 9 .

18. Vrsalovic M, Vucur K, Vrsalovic Presecki A, Fabijanic D, Milosevic M. Impact of diabetes on mortality in peripheral artery disease: a metaanalysis. Clin Cardiol. 2017;40(5):287-291. 


\section{Publish your work in this journal}

Clinical Interventions in Aging is an international, peer-reviewed journal focusing on evidence-based reports on the value or lack thereof of treatments intended to prevent or delay the onset of maladaptive correlates of aging in human beings. This journal is indexed on PubMed Central, MedLine,

CAS, Scopus and the Elsevier Bibliographic databases. The manuscript management system is completely online and includes a very quick and fair peer-review system, which is all easy to use. Visit http://www.dovepress. com/testimonials.php to read real quotes from published authors. 